\title{
nuevas instalaciones para el arsenal de la Armada Nacional
}

República Argentina

MARIO KALEMKERIAN, arquitecto Colaborador: E. TAROCO, ingeniero

\section{sinopsis}

La creación de un plan de construcciones nuevas y remodelación de las antiguas en el dique de la Armada Nacional, se aprovechó para realizar toda una serie de instalaciones necesa-
rias de servicio para el personal civil de dicha rias de servicio para el personal civil de dicha organización.

Para ello, y dado que la superficie disponible era muy limitada, se recurrió a: demolición de más acordes con las necesidades actuales, y ampliación del número de plantas en las edificaciones existentes. Para la ampliación del comedor, vestuarios y viejo edificio, en el que se sustituyó la cubierta por un forjado de losas huecas, prefabricadas, de hormigon armado. La planta alta asi formada se cubrió con bóvedas autoportantes, tambien prefabricadas, de ceramica, cuyos tímpanos se realizaron a base de hormigón ar-

La Oficina de Relaciones Laborales ocupa un recinto circular, con muros de bloques de horla que se cubre.

empleo de procedimientos constructivos radios axiliares utización de importantes memamente precisa, rápida y económica, en Ia que se conjugan la prefabricación de elementos en serie, a pie de obra, con el sistema de construcción tradicional.
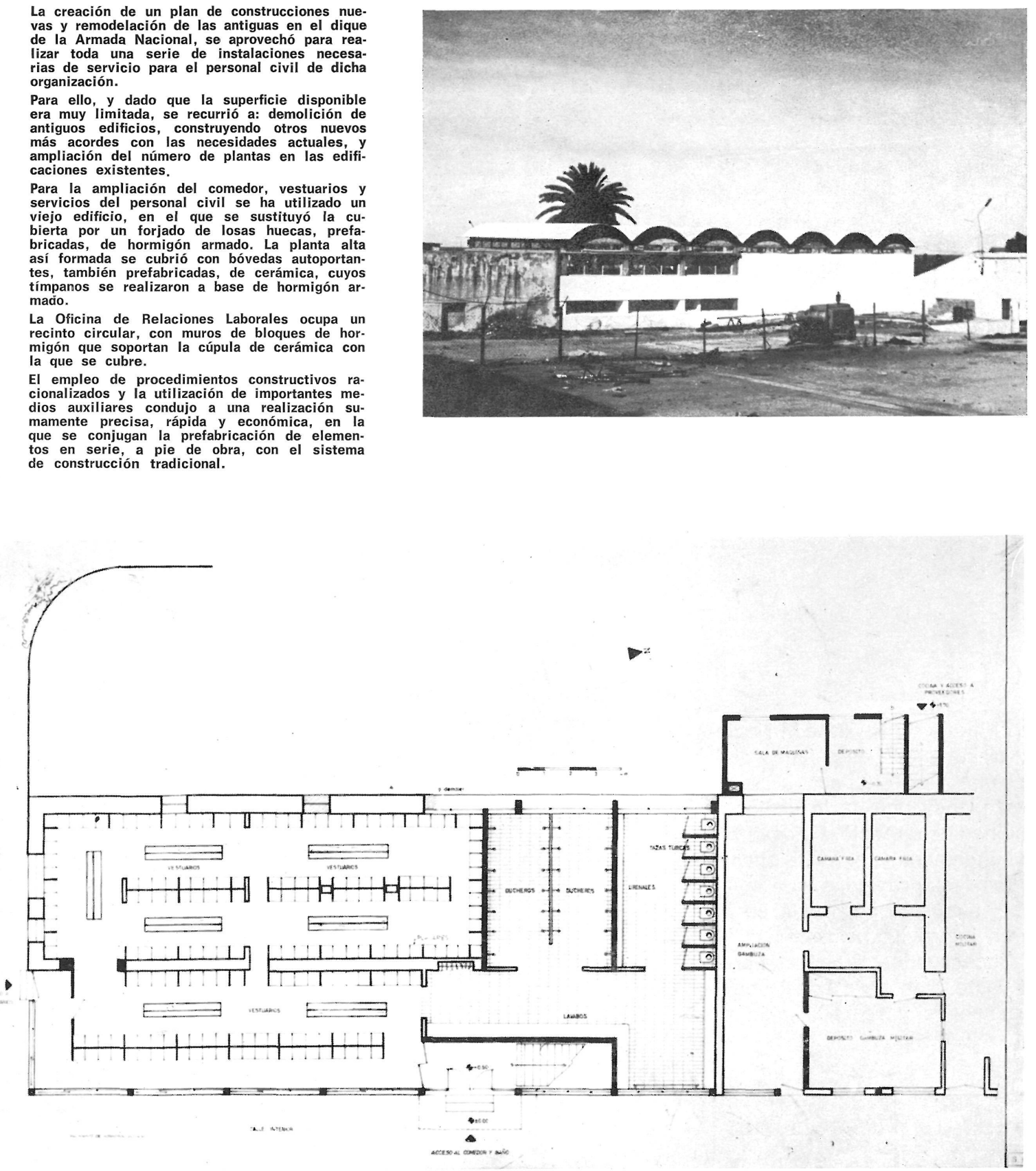

planta baja 


\section{planta alta}

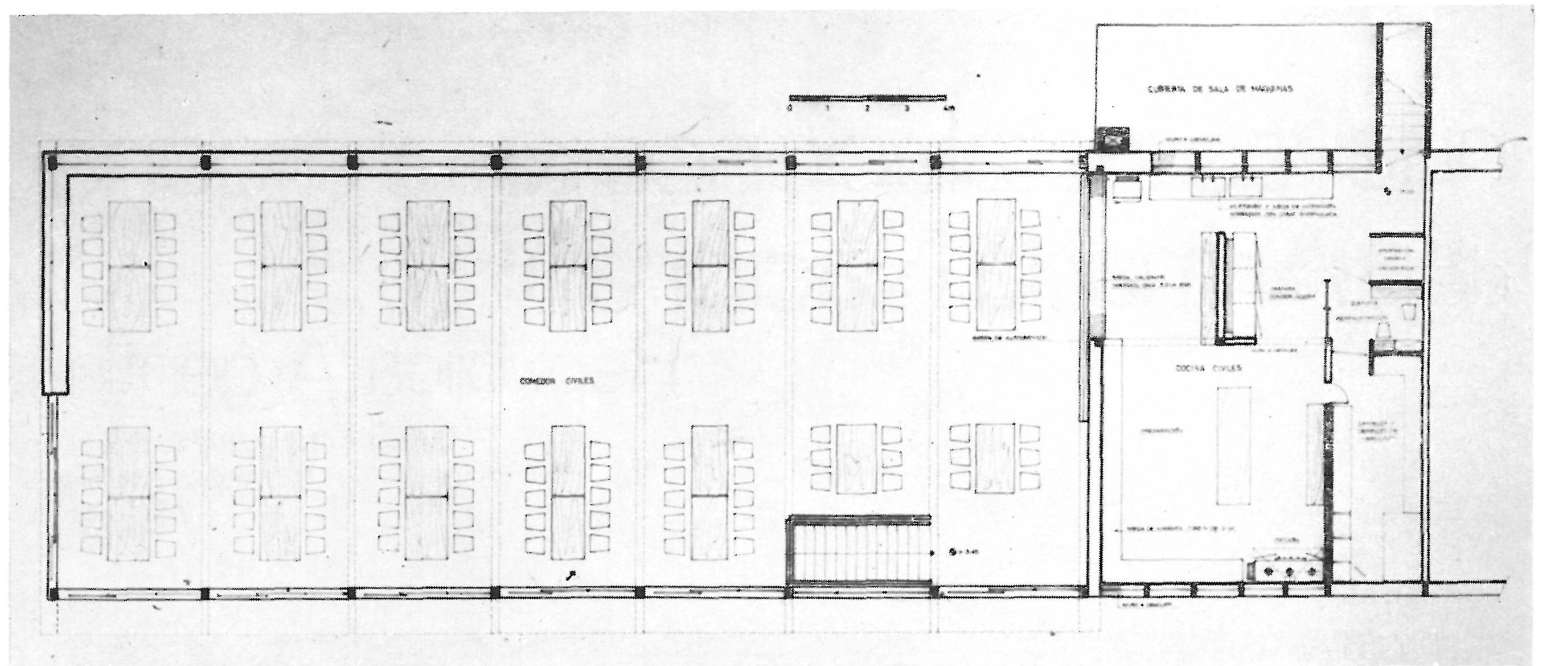

\section{entramado de entreplanta}

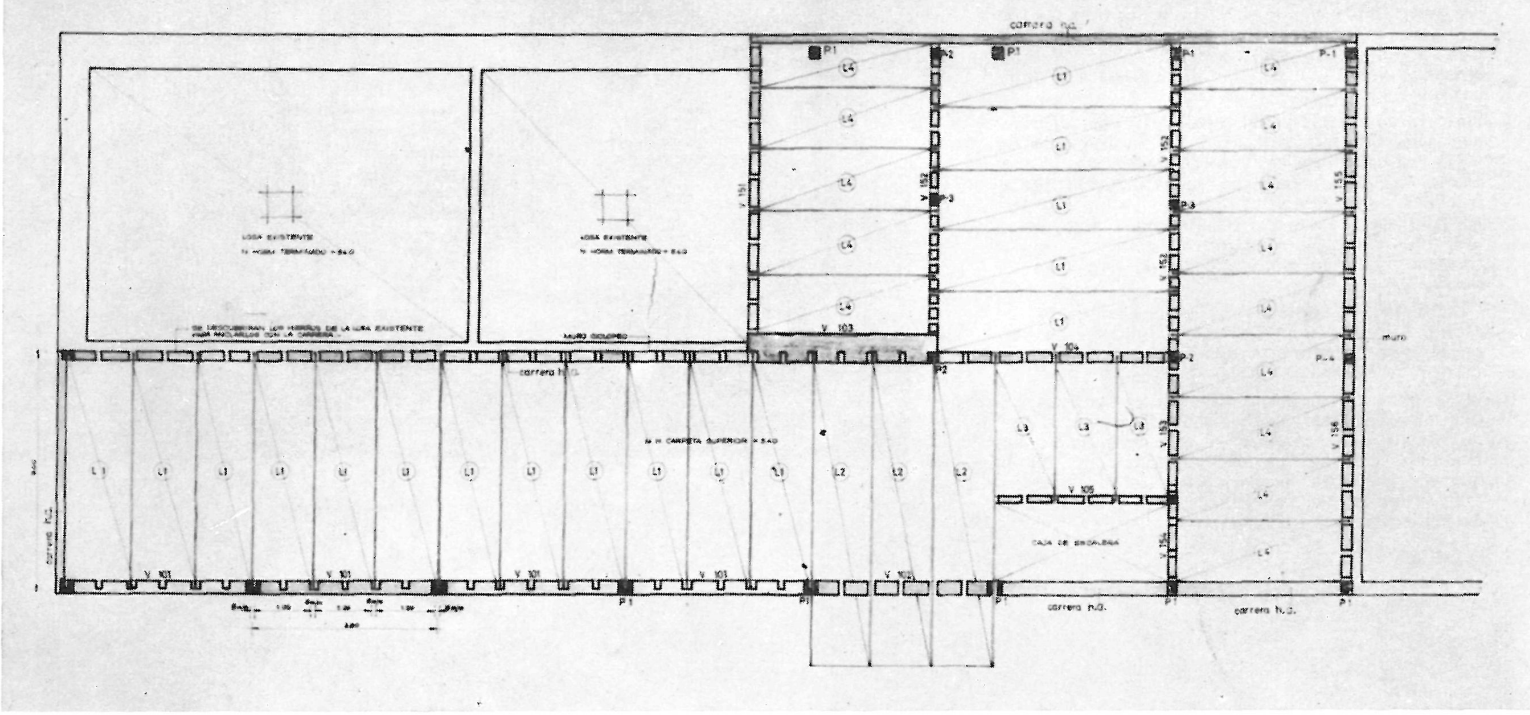

En el dique de la Armada Nacional trabajan 350 empleados civiles que necesitaban, urgentemente, toda una serie de instalaciones de servicio. Estaban tan mal atendidos, por no disponer de locales apropiados, que incluso el almuerzo se servía en lugares improvisados, a todas luces inadecuados. Cuando se creó un vasto plan para construcciones nuevas y remodelación de

\section{losas huecas prefabricadas}

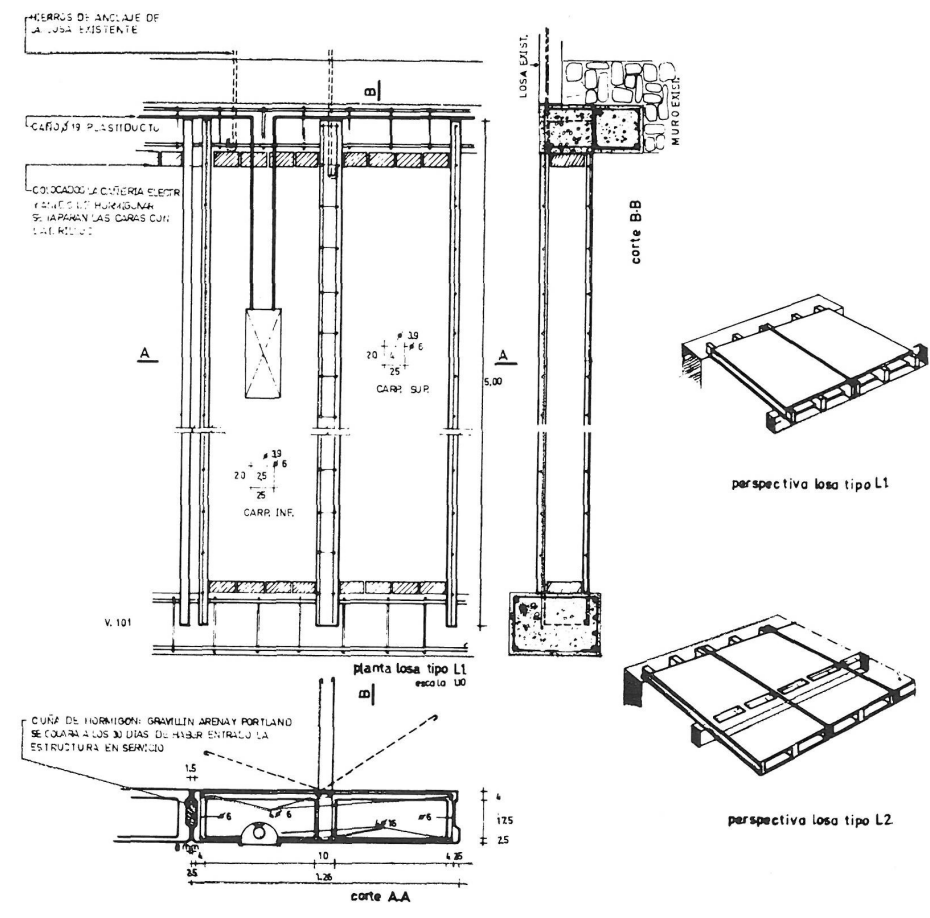



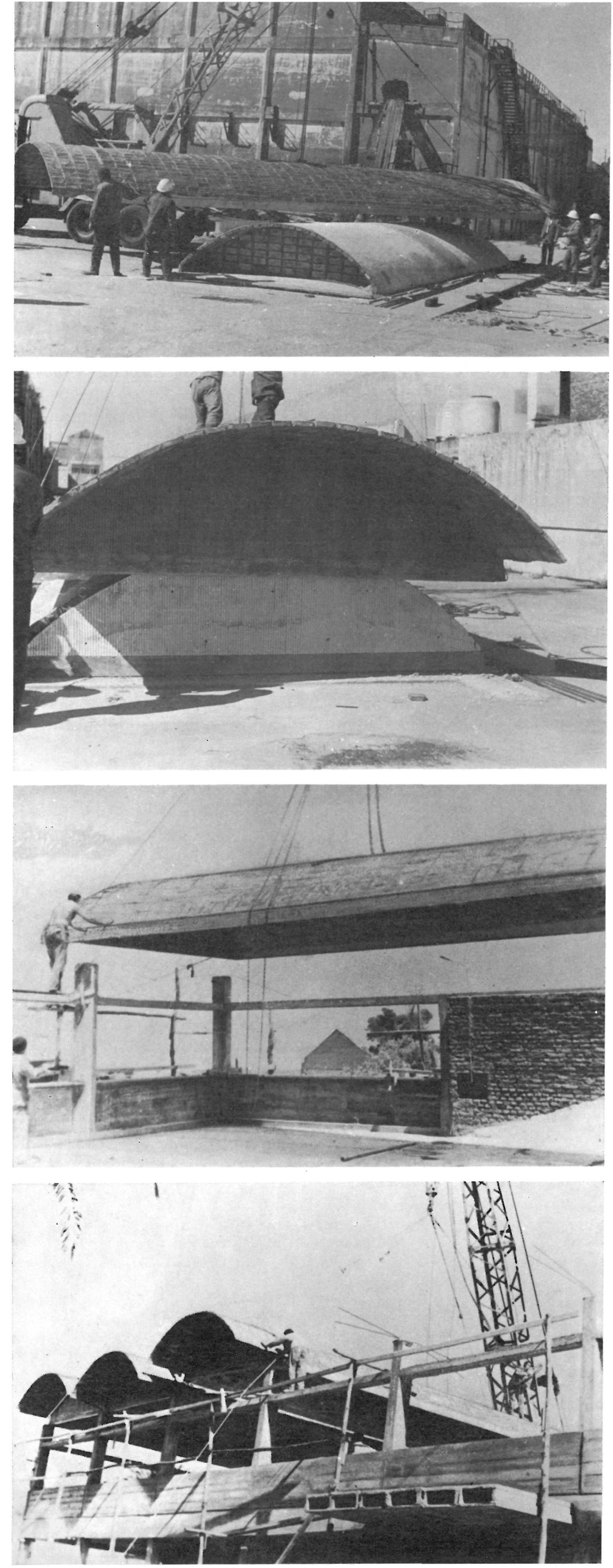

las existentes, se pensó en dar primacía a este problema, por lo que las obras del comedor, vestuario y servicios para dicha plantilla de trabajadores ocuparon un lugar primordial dentro del plan.

Las superficies existentes para construcciones de nueva planta eran muy limitadas, lo cual obligó a buscar diversas soluciones para resolver el problema. Fue preciso basar el planeamiento en la renovación, demoliendo antiguos edificios, para construir otros modernos, mejor adaptados a las necesidades actuales y con mayor aprovechamiento del espacio disponible. Otro sistema consistió en aumentar el número de plantas de las construcciones anteriores. En ambos casos se conseguía aprovechar exactamente la superficie en planta ya utilizada con anterioridad.

Uno de estos edificios antiguos se eligió para la ampliación que se necesitaba. Es una construcción que data de fines del siglo pasado; está rodeada perimetralmente de pesados muros de piedra, que llegan incluso a cubrir buena parte del contorno de la planta alta. La fachada oeste limita con terrenos de otra propiedad, a la que se pudo expropiar, una vez comenzadas las obras, una franja longitudinal de 13 metros de anchura, que fue un gran alivio para el desenvolvimiento del edificio. 
La planta baja estaba ocupada por la Oficina de Relaciones Laborales, la cual siguió funcionando en este lugar hasta que se construyó un local especialmente adecuado para ella. La cubierta antigua, constituida por una serie de cerchas, fue sustituida por un forjado de hormigón armado, tomándose este nivel como base general para la nueva planta. Dicho forjado se realizó mediante losas huecas prefabricadas, construidas a pie de obra, en la calle pavimentada existente al borde del edificio. Los encofrados para realizar estas piezas eran unos moldes toscos, fabricados con tablones de pino Brasil y equipados con unas guías metálicas para evitar su deformación. El acabado de la cara vista de las distintas piezas se consiguió con el mismo tipo de encofrado, pero recubierto de papel para facilitar el despegue al día siguiente de hormigonar.

Al colocarse las losas en obra quedaron unas juntas que se rellenaron con mortero de cemento, gravilla y arena, lográndose así la continuidad de las piezas por el efecto de cuña, que además permitía absorber los esfuerzos cortantes. El monolitismo de todas estas piezas se completó con el hormigonado de las vigas de borde y de las carreras de asiento. Este procedimiento de prefabricación y puesta en obra ofreció grandes posibilidades en cuanto a libertad de movimientos debajo de los forjados, ya que no necesitaban apuntalamientos.

La planta así construida se cubrió con bóvedas autoportantes, prefabricadas, de cerámica, realizadas a pie de obra en terrenos de la propiedad vecina que pudieron ser ocupados para este fin. Las piezas están moduladas de forma que a cada una le corresponden tres losas del forjado inferior. Tienen $13 \mathrm{~m}$ de luz total, $1 \mathrm{~m}$ de flecha y un peso aproximado de $6 \mathrm{t}$, coincidiendo su espesor con el del ladrillo con el que fueron realizadas, es decir: $5 \mathrm{~cm}$. Los tímpanos de las bóvedas, distanciados $11 \mathrm{~m}$, no son cerámicos, sino de hormigón armado. Van provistos de cuatro ganchos anclados a las armaduras antes del fraguado, que sirven para levantar la pieza del lugar donde se fabrica y colocarla posteriormente en el sitio definitivo. Los tímpanos van apoyados sobre cuatro pilares por intermedio de una lámina de goma, a la que, previamente, se le habían practicado los orificios correspondientes para permitir el paso de las barras de anclaje de los pilares y el del tubo de las conducciones eléctricas, colocado antes del hormigonado de dichos pilares.

Para facilitar el trabajo de prefabricación de estos elementos constructivos se hizo una bóvedamolde, de material cerámico, con cimbras deslizantes. Se obtuvo así una pieza de ladrillo que se alisó con arena y portland, evitando puntos angulosos para no dificultar el despegue al des-

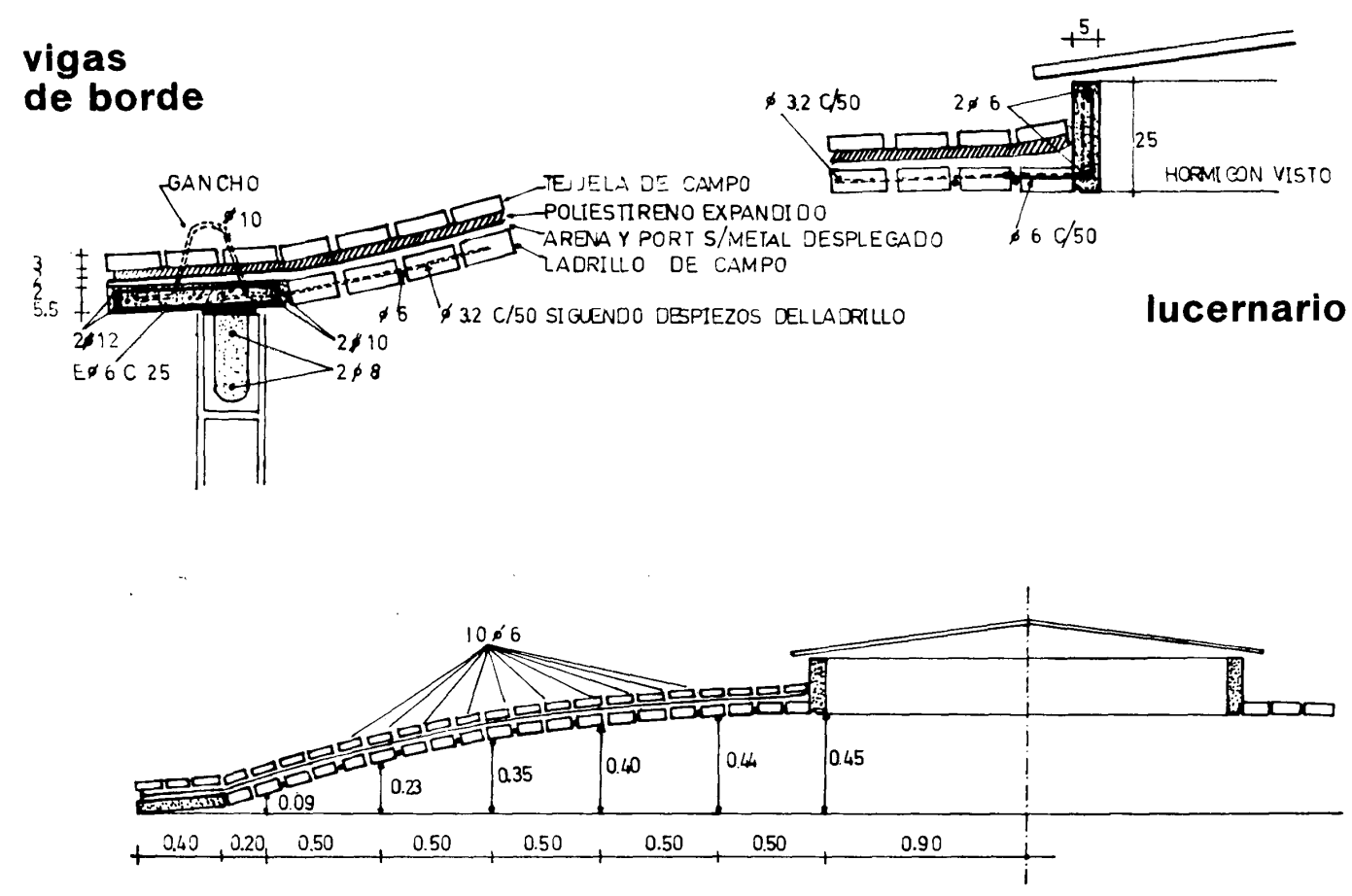

\section{cúpula cerámica armada}


encofrar. Por esta misma razón se inclinaron ligeramente las vigas de borde. Mediante esta bóveda-molde se efectuó el encofrado interior y exterior de los tímpanos de las bóvedas definitivas. Las caras interiores se separaron $5 \mathrm{~cm}$ de la bóveda - molde, cubriéndolas con chapa para que, en la maniobra de elevación, cayera el encofrado interior sin dificultad, conjuntamente con la chapa colocada en el borde.

Una vez colocadas todas las bóvedas en su posición definitiva, se doblaron los hierros de anclaje de los pilares y las varillas de las vigas de borde para darles continuidad a las láminas adyacentes. Asimismo se colocó una malla electrosoldada, de $3 \times 15 \times$ $\times 15 \mathrm{~mm}$, que fue recubierta con una capa de mortero de cemento, arena y gravilla, cuidándose su curado posterior. Finalmente, los elementos se terminaron con dos manos de pintura blanca al cemento.

La instalación eléctrica de la nueva planta se resolvió con un sistema de cables que, yendo por los tubos colocados dentro de los pilares, afloran por la parte superior de los mismos. Después se llevan horizontalmente a través de la separación entre los espacios de las bóvedas, para, por último, embutirse en las cajas ya previstas. Los tubos que portan los cables para la instalación eléctrica de la planta inferior se condujeron por las losas huecas prefabricadas. En la cara inferior de las mismas, que se corresponden con el cielorraso de la planta, se colocaron las luminarias correspondientes.

La calefacción de los locales se obtiene mediante radiadores de agua caliente, cuyas cañerías se dejaron vistas, al igual que las de agua fría y caliente de la instalación sanitaria.

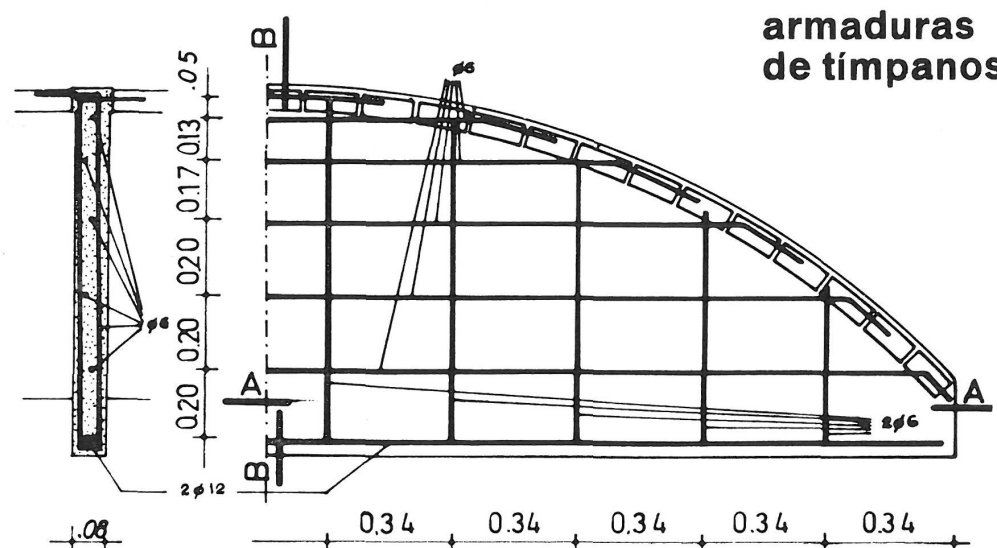

Corte B-B

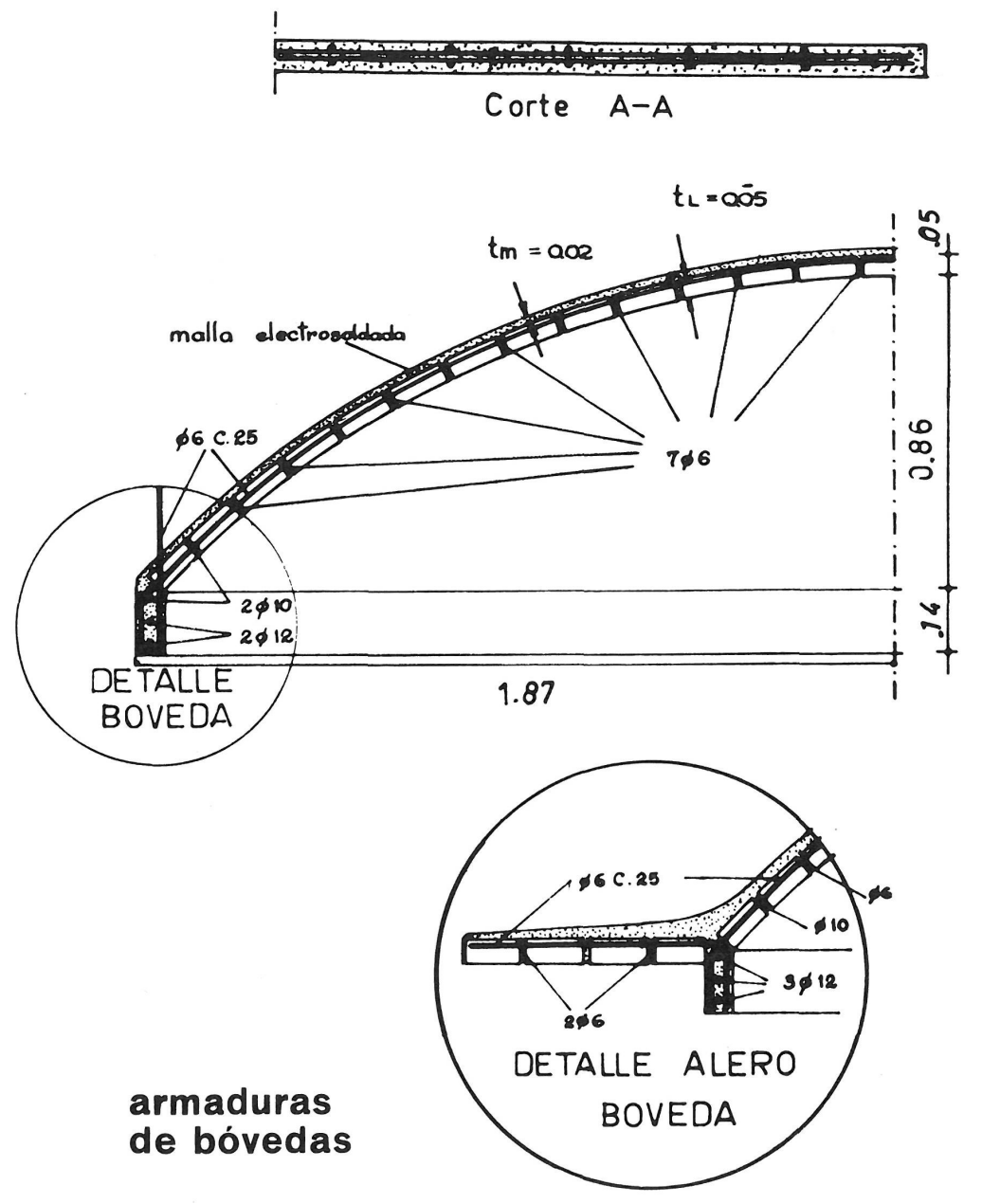

armaduras de bóvedas 


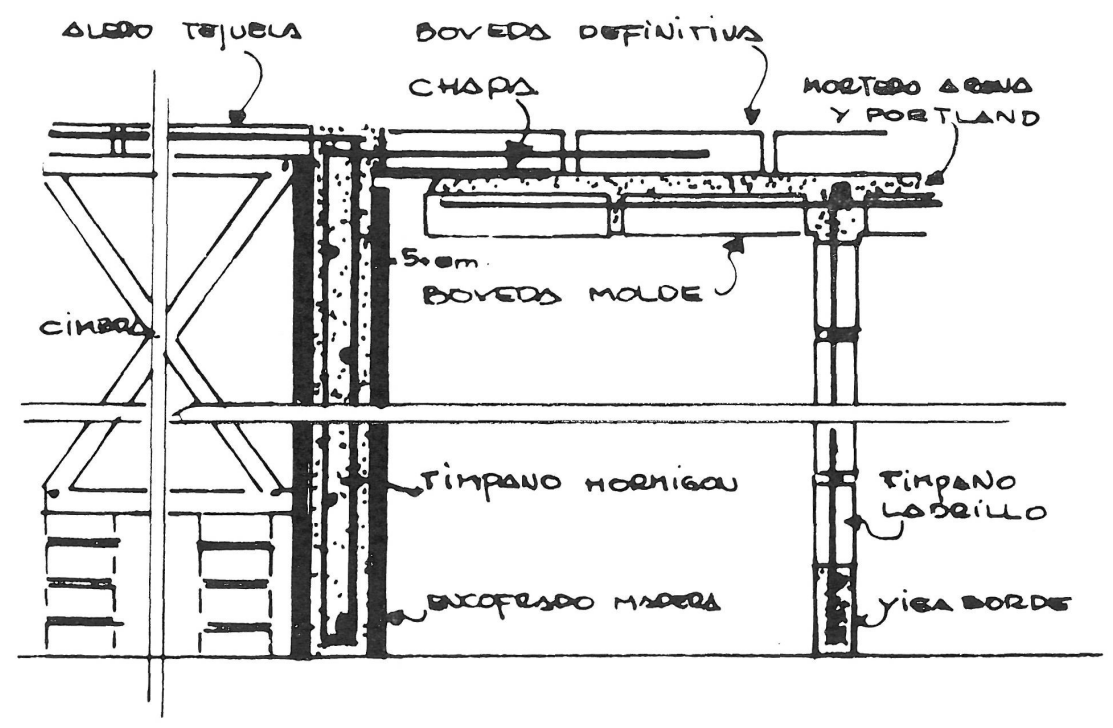

\section{detalle de alero de las bóvedas}

Para todas las obras se pudo disponer de una grúa montada sobre orugas, con una pluma de $18 \mathrm{~m}$ de longitud y capacidad de $6.000 \mathrm{~kg}$. Esta pluma pertenecía al parque de maquinaria del Arsenal y se empleaba habitualmente en la reparación de barcos. Dado que la forma en que estaban programados los trabajos en el dique dejaba momentos libres a la grúa, se pensó en su utilización por el ahorro considerable que esto suponía, toda vez que, además, se empleaba el mismo personal que la manejaba normalmente y sin interrumpir las actividades usuales para las que estaba destinada. Se convirtió en un importante elemento para elevar y colocar en obra las piezas prefabricadas hasta ahora reseñadas y, sobre todo, para la cúpula de la Oficina de Relaciones Laborales.

Para esta Oficina se construyó un local circular, con muros formados por bloques de hormigón asentados directa-

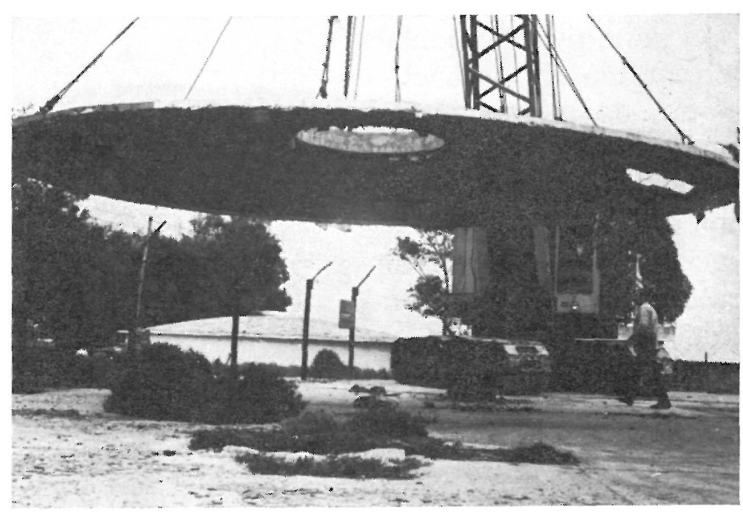
mente sobre un pavimento del mismo material. Se realizó lo suficientemente resistente para que fuese capaz de soportar el peso propio del muro más el de la cubierta cupular de cerámica, que supone una carga de unos $200 \mathrm{kp} / \mathrm{m}$. Esta cúpula tiene $8 \mathrm{~m}$ de diámetro y $40 \mathrm{~cm}$ de flecha. Para construirla se utilizó un encofrado que es la tapa de un tanque de agua, situado en un lugar próximo a la construcción. Esta tapa es, a su vez, una pieza de hormigón armado realizada con arena mojada y compactada como encofrado. La cúpula de cerámica presenta un lucernario que fue sugerido por la propia tapa, al llevar ésta, en la misma zona, el acceso al tanque. Uno de los sectores, el correspondiente al lugar del flotador de la tapa, quedó sin terminar, cubriéndose, posteriormente, una vez colocada la cúpula en su emplazamiento definitivo. 
Los ladrillos que sirvieron para la construcción de la cúpula se colocaron trabados, siguiendo el sentido de generación de la misma. Cada dos hiladas se interpuso una varilla de $6 \mathrm{~mm}$, a modo de estribos, que seguían las juntas de despiece de los ladrillos. El empuje se resolvió con una viga de hormigón armado cuya altura coincide con el espesor del ladrillo, en la que se dejaron seis ganchos para facilitar la elevación de la cúpula. Una vez colocada ésta en obra, se cubrió con chapa plegada, la cual, a su vez, fue protegida con una capa de mortero de cemento de $2 \mathrm{~cm}$ de espesor. También se colocó una capa aislante de placas de poliestireno expandido, y se protegió con tejas de $3 \mathrm{~cm}$ de espesor.

Finalizado este local se trasladó a él la Oficina de Relaciones Laborales, situada hasta entonces en la planta baja del otro edificio. En el lugar que dejó libre se dispusieron los vestuarios y servicios para el personal civil del Arsenal de la Armada.

Los procedimientos constructivos empleados en estas obras reportaron una serie de importantes experiencias y ventajas. Por ejemplo, con la prefabricación in situ de las piezas se eliminaron los encofrados en obra y el transporte de las mismas, repercutiendo en un considerable ahorro. El plan de obra, gracias a la utilización de estos elementos, se pudo hacer mucho más preciso, con unos diagramas flexibles que permitieron simultanear muchas especificaciones. Esta mayor planificación, unida a una mejor supervisión, dio lugar a que las dosificaciones del hormigón resultaran sumamente precisas, ahorrándose material al poderse considerar tensiones admisibles de valor más alto que lo normal. Toda esta organización contribuyó a un rápido adiestramiento del personal no acostumbrado a este tipo de realizaciones, ya que las distintas operaciones pudieron reducirse a movimientos elementales y repetidos.

Con estos procedimientos se buscó relacionar la prefabricación de elementos en serie a pie de obra, con el sistema tradicional de construcción.

\section{résumé}

Nouvelles installations pour l'arse. nal de la flotte nationale - République argentine

Mario Kalemkerian, architecte

Collaborateur: E. Taroco, Ing.

La création d'un plan de nouvelles construc tions et de remodelage des anciennes dans le dock de la Flotte Nationale argentine
servi à la réalisation de toute une série d'installations nécessaires de service pou le personnel civil de cette organisation.

Pour cela, et étant donné que la surface disponible était très limitée, on a eu recours à la démolition des anciens bâtiments et à la construction d'autres nouveaux plus
conformes aux besoins actuels, et à l'aug. mentation du nombre de niveaux des bâti.
ments existants. ments existants.

Pour l'agrandissement du réfectoire, vestiaires et services du personnel civil on a utilisé un vieil immeuble, dont la couverture a été remplacee par un hourdis creux, prefabriqué, en beton armé. Le niveau supéauto-portantes, également préfabriquées, de céramique, dont les tympans ont été exécutés en béton armé.

Le bureau des Relations Techniques occupe un local circulaire, dont les murs en blocs de béton supportent la coupole de céramique qui couvre ce bureau.

L'emploi de procédés constructifs rationa. lisés et l'utilisation d'importans moyens auxiliaires a conduit à une réalisation ex trêmement précise, rapide et économique, dans laquelle sont conjugués la préfabrica et le système de construction traditionnelle.

\section{summary}

New installations for the National Navy - Republíc of Argentina

Mario Kalemkerian, architect

At the design of a project for remodelling the old building and constructin new ones at the dock of the National Navy of Argen ina, several additions were introduced to provide the civil staff with necessary ins-

In view of the fact that the available space was quite restricted, the work was carried out in the following way: demolition of old buildings, construction of new ones to meet present requirements and increase of
the number of storeys in the already existing buildings.

For the enlargement of the dining room wardrobes and other service sections of the civil staff, one of the old buildings has been used, where the roof was replaced by a prefabricated hollow hoor of reinforced concrete. Whe thus formed upped floor was valts, the cores of which are of reinforced concrete.

The Labour Relations Office occupies a circular shaped area with walls of concrete

Thanks to the use of rationalized construc tion procedures and to the use of importan auxiliary means, the work was carried out in a precise, rapid and economical manner by mixing members that were prefabricated construction system.
in series on the site

\section{zusammentassung}

Neue anlagen der Nationalen Kriegsflotte - Argentinien

Mario Kalemkerian, Architekt

Mitarbeiter: E. Taroco, Ing.

Bei dem Entwurf für den Umbau der älteren Gebaude und fur die Konstruktion neuer flotte, wurden gleichzeitig zusätzliche, für das Zivilpersonal erforderliche Anlagen mit in Betracht genommen.

Da die verfügbare Gesamtfläche verhältnismässig begrenzt war, wurde die Arbeit folgenderweise ausgeführt: Abtrag der älteren den gegenwärtigen Bedürfnissen entsprechen sollen, und zuletzt Vermehrung der bereits existierenden Stockwerke.

Für den Ausbau des Speisesaals und Garderoben wurde das alte Gebäude ausgentzt, körperdecke aus Stahlbeton ersetzt wurde. Die hierbei entstandene Oberetage wurde mit salbsttragenden, auch vorgefertigten, Terracottagewölben versehen, deren Bogenfelder aus Stahlbeton sind.

Das Arbeitsamt nimmt ein kreisförmiges den Mauern, die das Kuppelgewölbe tragen. Indem rationelle Baumethoden und bedeutende Hilfsmittel gebraucht wurden, konnte die Arbeit in einer exakten, schnellen und ökonomischen Weise ausgeführt werden, in der sich in Serie und auf dem Bau vorgefertigte mischen. 